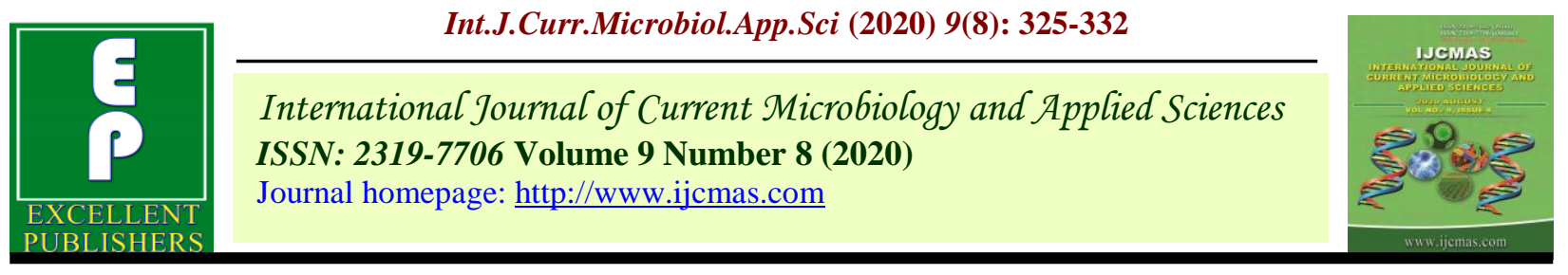

Original Research Article

https://doi.org/10.20546/ijcmas.2020.908.038

\title{
Optimization of CTAB-based RNA Extraction Method for Aspergillus flavus
}

\author{
Virali Antala*, Hemangini Chaudhari, Nidhi Radadiya, Hiral Desai, \\ B. A. Golakiya and H. P. Gajera \\ Department of Biotechnology, Junagadh Agricultural University, Junagadh, Gujarat, India \\ *Corresponding author
}

\section{A B S T R A C T}

\begin{tabular}{|l|}
\hline Ke y w o r d s \\
Extraction; Fungi; \\
Real time; PCR; \\
RNA \\
\hline Article Info \\
\hline $\begin{array}{l}\text { Accepted: } \\
\text { 10 July } 2020 \\
\text { Available Online: } \\
\text { 10 August } 2020\end{array}$ \\
\hline \hline
\end{tabular}

High-quality RNA extraction are very important for further downstream molecular applications such as transcript amplifications by reverse transcriptase-polymerase chain reaction (RT-PCR) and elaboration of cDNA for expressed gene study. Aspergillus flavus is the paramount aflatoxin producing fungus in cultivated oil seeds. The methodology with some modification is described here that allows the intact RNA isolation from mycelium. RNA quality was evaluated by electrophoresis in agarose gel, quantitative Real-Time PCR of cDNAs derived from isolated mRNA and subsequent PCR amplification using primers designed against $\beta$-tubulin and $\mathrm{aflO} / \mathrm{omtB} / \mathrm{dmt} / \mathrm{O}$ methyltransferase $\mathrm{B}$ from A. flavus.

\section{Introduction}

Aspergillus species is a filamentous, pervasive saprophytic fungus mainly found in soils and distributed widely across the world. The fungus frequently contaminate various grain and oil seeds crops during pre- and postharvest (Perrone et al., 2007) period. Aspergillus is a diverse genus with social inequalities and exhibit immense ecological with metabolic differences (Asan, 2004). The priest and botanist Antonio Micheli in 1729 first described the name of Aspergillus due to its corresponding asexual spore-bearing structure called as aspergillum, which is reminded the shape of holy water sprinkler used in some Christian ritual services. Mainly
Aspergillus describes the reproductive sexual and asexual cycle of the filamentous fungus. They are filamentous multiracial species mainly found in soil, plant or animal debris and indoor environment (Geiser, 2009).

Aspergillus taxonomy is ever evolving and complex. Aspergillus genus based on physiological, genetic and morphological similarity contains different 185 species within 18 groups, as a member of a fungi largest phylum Ascomycota. Aspergillus strains were studied by their growth characters, extrolite profiles, macro and micro morphology and $\beta$-tubulin gene sequences. By its conidiophore characteristic (a conidium-bearing hypha or filament) 
Aspergillus genus is easily identified. But the identification and differentiation of species is traditionally based on morphological features and it is quit complex, generally the macro morphological features include mainly colony diameter, colony reverse colour, colony edge, conidia and mycelia colour, production of exudates and soluble pigments, presence of sclerotia and cleistothecia while micro features is dependent on vesicle's seriation, size and shape, morphology of conidia and stipe as well as ascospores, cleistothecia and presence of Hulle cells.

Aspergillus sub genus group Flavi refered to as the Aspergillus flavus, has gained attention ubiquitously due to its toxigenic nature and different use in industry. Section Flavi is divided into toxigenic and nontoxigenic groups of species. The widely distributed aflatoxigenic species includes $A$. flavus and $A$. parasiticus. Several other mycotoxigenic species which may produce toxic compound other than aflatoxin include Aspergillus carbonarius, A. alliaceous, A. flavipes, A. fumigatus, $A$. nomius, $A$. tamari, $A$. versicolor, A. terreus, A. niger, A. bombycis, A. ochraceoroseus, A. pseudotamari, etc (Klich, 2007). Out of these some species like A. fumigatus and A. niger are pathogenic and hazardous to animals and humans. This group can cause major problems in agricultural field stock and products worldwide. The nonaflatoxigenic species include $A$. tamarii, $A$. sojae and mainly $A$. oryza is used as a starter culture for the preparation of fermented foods as well as in alcoholic beverages. Moreover it is also an important source of starch processing enzymes such as alpha-amylases, glucoamylase and proteases used for brewing and baking purpose across worldwide (Machida and yamada, 2008). While in Asia A. sojae and A. tamarii are used traditionally for fermented foods production (Cotty and Garcia, 2007). Mainly toxic and non-toxic Aspergillus strains were differentiated based on morphological and toxic potential of individual species (Machida and Yamada, 2008).

Contamination of groundnut with toxic aflatoxin content is the result of an extensive interaction of seed and toxic A. flavus fungi. The aflatoxin accumulation in groundnut seed is directly depends on sequential pathosystem interaction of $A$. flavus penetration, growth and development (Kumeda and Asao, 2001). In crops the management of aflatoxin contamination is enticed by the study on the aflatoxin synthesis pathway during hostpathogen interaction (Dorner et al 2002). To prevent contamination of aflatoxin, it is significant to elucidate the molecular mechanisms which regulate the growth, development and secondary metabolites production during colonization of A. flavus in groundnut seed. Now a day, the RNA-seq approach is very applicable to accelerate the in depth study of an organism's gene regulation, co-expression and metabolic network under various stress conditions. The comparative RNA-seq approach has quantified more accurate and efficient gene expression than by conventional transcriptome study (Georgianna et al., 2010).

Filamentous A. flavus are prominent with its combat, strong and rigid cell walls which poses higher levels of 50 to $60 \%$ of $\alpha-1,3$ glucan, chitin and other than this the presence of high level of Manno-protein and polysaccharides with secondary metabolites in fungal cell wall make it resist to lyse (Bakri et al., 2009). The total RNA isolation process is difficult in fungus due to the presence of carbohydrates which gets co precipitate along with RNA, which can also interfere during mRNA enrichment from total RNA.

Majority of RNA extraction methods generally use mechanical or mechanicalphysical techniques directly to breaks the cell 
wall components, such as disruption with grinding in liquid nitrogen, using glass beads, mill grinding, alternating freezing and thawing (Griffin et al., 2002). The cell wall disruption are often combined which include the processing of the sample with combination of ultrasound (microwave radiation) and lysis buffer which contain cationic (CTAB- cetyltrimethylammonium bromide) and anionic detergent sodium dodecyl sulphate. Depending on the fungal cell wall chemical composition, some enzymes like cellulose, lysozyme and chitinase are also used for the cell lysis. In lysis buffers SDS or CTAB is a major component in combination with $\mathrm{NaCl}, \beta$ mercaptoethanol and PVP. Proteinase $\mathrm{K}$ is mainly use to digest protein. Mainly the precipitate of RNA is carried out through Phenol-chloroform solvent extraction followed by isopropanol or ethanol.

Best RNA extraction procedure for fungi, similarly for all organisms with rigid cell walls are based on 1. Grinding in liquid nitrogen, 2. Denaturing proteins and extracting RNA with guanidinium thiocyanate and 3. Separating RNA from proteins and DNA by centrifuging the dense RNA through an ultracentrifuge rotor by phase separation (Sanchez-Rodriguez et al., 2008). The most difficult steps to extract the RNA from filamentous Aspergillus fungi, is to disrupt the cell wall which is rich source of phenols and polysaccharides, without causing damage to RNA. Once the cell wall disruption is carried out by detergents like SDS or CTAB, it leads to release the phenolic compounds, which gets oxidise quickly and binds covalently with nucleic acids. During RNA precipitation the oxidized phenol gets co-precipitate with RNA which makes RNA difficult to precipitate and dissolve. Finally decrease the high quality of RNA. In order to overcome this problem various antioxidant compound like PVP and $\beta$-mercaptoethanol with lysis buffer is used.
Which form $\mathrm{H}$-bond with polyphenol compound and this co-precipitate complex were removed or separated by high speed centrifugation by chloroform: isoamyl alcohol phase separation step (Poon et al., 2019).

\section{Materials and Methods}

A. flavus toxic (AFJAU 2) and non-toxic fungi (AFNRRL 21882) suspension culture were prepared. Healthy mature seed of aflatoxin resistant J-11 and susceptible GG-20 seeds were surface sterilized and then in vitro seed inoculation of both fungi was carried out and seeds were incubated for total 10 days. And seeds were selected based on seed showing maximum infection. After the $8^{\text {th }}$ day of incubation fungi samples were selected for further analysis.

Standard TRIZOL method was successful for RNA isolation from filamentous fungi in combination with CTAB (a detergent) (Patyshakuliyeva et al., 2014). Using this protocol, cell walls of fungal mycelia are broken down by grinding in pre chilled mortar and pestle using liquid nitrogen. Powdered mycelia were homogenized in $0.75 \mathrm{~mL}$ CTAB lysis buffer (100 mM Tris-HCl (pH 7.5), $5 \mathrm{M}$ $\mathrm{NaCl}, 0.5 \mathrm{mM}$ EDTA, $1 \% \mathrm{CTAB}$ and $1 \%$ PVP) and $1 \% \beta$-mercaptoethanol was added to the $\mathrm{CTAB}$ buffer prior to the extraction followed by incubation into water bath at $65^{\circ} \mathrm{C}$ for $10 \mathrm{~min}$ and mix gently during this incubation time interval. Followed by addition of an equal volume of acid phenol ( $\mathrm{pH}: 4.5)$ to the mixture, vortex drastically for $5 \mathrm{sec}$ and then centrifuge it at 13,000 rpm for $10 \mathrm{~min}$ at $4^{\circ} \mathrm{C}$. Subsequently the supernatant was extracted twice with addition of equal volume of phenol: chloroform (24:1) into the supernatant. The tubes were shaken vigorously for 1 to $2 \mathrm{~min}$, cooled on ice for 10 min followed by centrifugation at $13,000 \mathrm{~g}$ for $15 \mathrm{~min}$ at $4^{\circ} \mathrm{C}$. During this phase separation step, the mixtures were separated 
into 3 phase including upper- aqueous phase middle-interphase and lower- Phenolchloroform phase. To precipitate the RNA, clear aqueous phase was transferred into a 1.5 $\mathrm{ml}$ new eppendorf vial with addition of $1 / 3^{\text {rd }}$ volumes of $8 \mathrm{M} \mathrm{LiCl}, 300 \mu \mathrm{l}$ of chilled ethanol and incubated overnight at $-20^{\circ} \mathrm{C}$. Next day the mixture was centrifuged for 15 min at $10,000 \mathrm{rpm}$ and the resulted RNA pellet was washed with $75 \%$ ethanol, air dried and dissolved into the $50 \mu \mathrm{l}$ of RNase free water.

\section{Quantification and visualization of RNA}

Integrity and purity of the total RNA was tested with agarose gel electrophoresis and Nano Drop $^{\text {TM }} 2000 / 2000$ ct. In this study, total RNA extracted from $150 \mathrm{mg}$ of mycelia powder. The extracted mRNA samples were further used for normal PCR and RT-PCR expression analysis study (Manonmani et al., 2005).

\section{RT-PCR Analysis}

The PCR primers for the gene encoding $\beta$ tubulin were: CCAAGAACATGAT GGCTGCT and R: CTTGAAGAGCT CCTGGATGG, for the aflO/ omtB/ dmtA/ Omethyltransferase $\mathrm{B}$ encoding gene $\mathrm{F}$ : GTTATCGGCGTGTCGCTCT and R: TCG GATTGGGATG TGGTC. RT-PCR was conducted in ABI-7500 Fast real time system following the instruction of the Quanti Fast SYBR Green PCR Master Mix (Genetix, USA) (Yamamoto et al., 2010).

The RT-PCR was performed using following program including initial denaturation $-94^{\circ} \mathrm{C}$ for $2 \mathrm{~min}$, repetition of 35 cycles with denaturation at $94^{\circ} \mathrm{C}$ for $30 \mathrm{~s}$, anneleaning at $60^{\circ} \mathrm{C}$ for $30 \mathrm{~s}$, and extension at $72^{\circ} \mathrm{C}$ for $66 \mathrm{~s}$ and a final extension was carried out at $72^{\circ} \mathrm{C}$ for $7 \mathrm{~min}$. Amplification products were analysed on $1.2 \%$ agarose gels.

\section{Results and Discussion}

Number of researchers has described the RNA extraction from various fungi by direct kit method but very few papers has deal with extraction of RNA by manual method from filamentous fungi. Schumann et al., (2013) extracted the good quality of RNA from Fusarium oxysporum mycelium grow on static liquid media/ membrane overlay cultures compare to the solid medium due to the agar contamination RNA pellets formed hard to re-suspend in water. Geoghegan et al., (2019) described the RNA extraction method from single fungal spores. Generally the RNA extraction from fungi by manual method is very difficult; similar to mammalian cell, RNA extraction from fungi cell is not easy. Mainly from plant and animal cell RNA is easily extracted due to easily cell lyses and high RNA content. There for they have use mechanical method using glass beads instead of chemical lyses to extract the RNA from single conidia. And successfully created first report of single spore transcriptomics data from $A$. niger fungi.

It is very critical to select appropriate detergent for high quality RNA extraction from different fungi sample based on chemical composition of cell (Chomczynski and Sacchi, 2006). In this study CTAB + Trizol is used for RNA extraction from filamentous fungi. CTAB lyses the cell wall component of fungi and prevent the degradation of RNA by protecting RNA from the endogenous RNase activity. As well as in TRIZOL also guanidium salt is an excellent RNase denaturant. It consists of 30 to $60 \%$ phenol and guanidium thiocyanate. Guanidinium thiocyanate being as a chaotropic agent mainly used to remove protein by degradation. (Tan and Yiap, 2009). It helps to separate RNA from RNA-protein complex and it deactivates the RNases enzymes that degrade RNA by denaturing 
these proteins. The principle basis of the modified protocol is that the use of acidic phenol solution during extraction leads to separation of RNA from DNA, followed by centrifugation using phenol and chloroform solvent mixture (Rubio-Pina and ZapataPerez, 2011). After centrifugation under low $\mathrm{pH} /$ acidic conditions, in aqueous phase total RNA remains present, while most of the impurities like proteins, phenol and DNA were co-precipitate into the lower organic phase or interphase. Followed by recovery of total RNA carried out by precipitating with ethanol and $\mathrm{LiCl}$. The $\mathrm{LiCl}$ efficiently precipitated high quality RNA without contamination of genomic DNA and small RNA, which was not visible on the gel (Fig: 1). In CTAB lysis buffer the chloride concentration is increased to more than $2 \mathrm{M}$ and can therefore prevent phenol and polysaccharide precipitation (Wang and Stegemann, 2010). The purity of successfully extracted RNA were checked by quantitative (optical density checking) and qualitative analysis by visualizing the RNA on $1.5 \%$ agarose gel electrophoresis and RT-PCR study using toxic and non-toxic fungl specific primers.

This RNA extraction method is modification of traditional CTAB-RNA extraction method of Shu et al., (2014) which does not require a high level of skill. Initially prior to purification extra steps are required to break down the cell wall with the use of Trizol with lysis buffer, as fungal cell walls are extremely complex, rigid and difficult to lyses by traditional extraction method.

Table.1 Qualitative and quantitative analysis of fungi RNA samples

\begin{tabular}{|l|l|l|l|l|}
\hline Sr. No. & Fungal samples & RNA(ng/ $\mathbf{\mu l})$ & $\mathbf{2 6 0 / 2 8 0}$ & $\mathbf{2 6 0 / 2 3 0}$ \\
\hline $\mathbf{1}$ & Control toxic fungi & 897.8 & 1.93 & 1.87 \\
\hline $\mathbf{2}$ & Control non toxic fungi & 835.9 & 1.97 & 1.97 \\
\hline $\mathbf{3}$ & F T- GG-20 & 818.5 & 2.06 & 2.08 \\
\hline $\mathbf{4}$ & F T-J11 & 942.7 & 2.03 & 1.87 \\
\hline $\mathbf{5}$ & F NT GG-20 & 998.3 & 2.00 & 1.83 \\
\hline $\mathbf{6}$ & F NT J-11 & 819.2 & 1.93 & 1.81 \\
\hline
\end{tabular}

Fig.1 Electrophoresis of total RNA isolated from 6 samples of toxic and non toxic A. flavus fungi

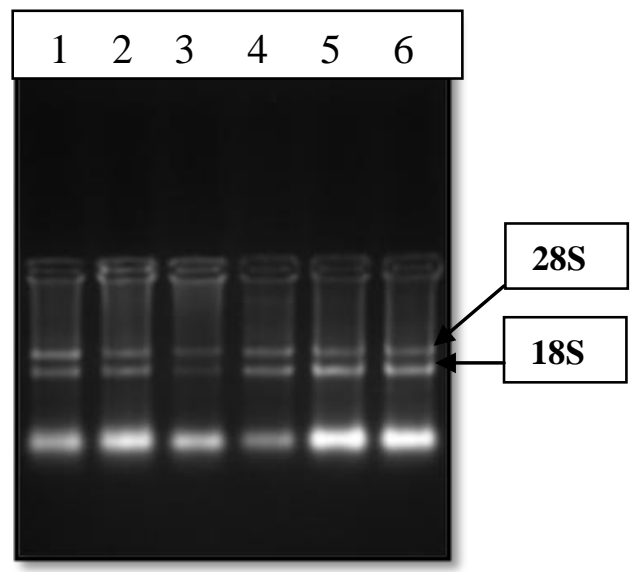

F- fungi, 1. Control toxic fungi, 2. Control non toxic fungi, 3. FT GG-20(S) = Toxic fungi in response to susceptible variety, 4. FT J-11(R) = Toxic fungi in response to resistant variety, 5. F NT GG-20(S) = Non-toxic fungi in response to susceptible variety and 6 . F NT J-11(R) $=$ Non-toxic fungi in response to resistant variety 
Fig.2 RT-PCR analysis of $\beta$-tubulin (A) and aflO/ omtB/ dmtA/ O-methyltransferase (B) using RNA extracted from 6 samples of toxic and non toxic A. flavus fungi
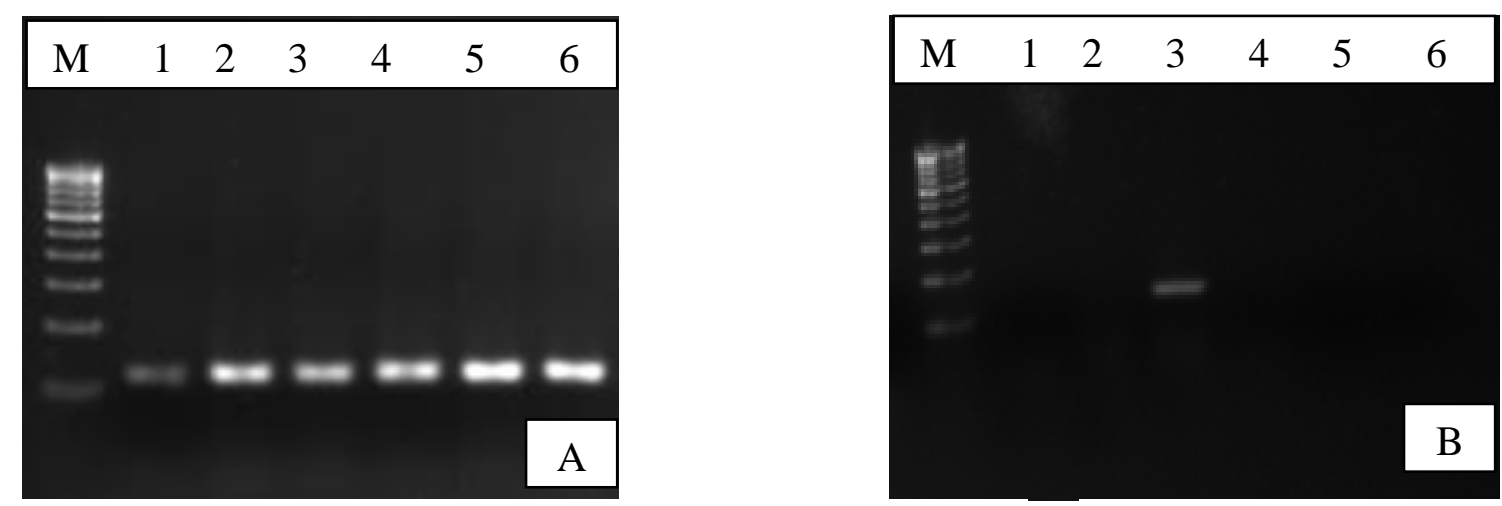

F- fungi, 1. Control toxic fungi, 2. Control non toxic fungi, 3. FT GG-20(S) = Toxic fungi in response to susceptible variety, 4. FT J-11(R) = Toxic fungi in response to resistant variety, 5. F NT GG-20(S) = Non-toxic fungi in response to susceptible variety and 6 . F NT J-11(R) $=$ Non-toxic fungi in response to resistant variety

\section{Quantification and visualization of RNA}

The samples of Aspergillus flavus processed with this methodology, the A260/A230 ratios were found to be in range of 1.9 to 2.0 (Table: 1) with high quantity of RNA. In general, an A260/280 ratio of 1.9 to 2.0 is considered high quality for RNA and to be free of contaminants (Lim et al., 2016). The yielded RNA with values of A260/280 (2.03 to 1.93) and A260/230 (2.08 to 1.81) indicates very low levels of contamination with proteins, polysaccharides and phenolics. Which emphasized the described method is capable to remove carbohydrates, protein and other impurities from fungal samples as shown in gel image clear and distant band of RNA without any shearing in the RNA preparations. The efficiency of the mRNA isolation drastically affected by the presence of carbohydrate or protein impurities. Mainly the impurities or carbohydrates block the process of enrichment of RNA by forming hydrophobic bond with the membrane matrix containing oligo dT require for poly A containing RNA purification column. Integrity and concentration of all the RNA samples were determined with agarose gel electrophoresis. All the samples were found to be free of DNA contamination which was clearly visible on the gel.

Very clear, intact and distinct $28 \mathrm{~S}$ and $18 \mathrm{~S}$ bands were examined by agarose gel electrophoresis which indicates the purity and quality of the total RNA extracted by these standardized protocol (Fig: 1). For all toxic and non toxic fungi sample, further validation and expression analysis of total RNA/mRNA was carried out by RT-PCR.

\section{Reverse Transcriptase PCR (RT-PCR)}

Since this method gave high purity and the highest quantity of RNA from both the type of fungi, further the suitability of extracted RNA were tested for reverse transcriptase PCR (RT-PCR). The total mRNA enriched with this protocol was applicable for RT-PCR (Fig. 2). A 124 bp fragment of $\beta$-tubulin was amplified from cDNA, which is reverse transcribed from the total RNA of toxic and non toxic fungi. While, $156 \mathrm{bp}$ fragment of aflO/ omtB/ dmtA/ O-methyl transferase B specific to aflatoxin biosynthesis gene was found to be present only in toxic fungi interaction with susceptible GG-20, remain absent in control, interaction of toxic fungi with resistant $\mathrm{J}-11$ as well as non toxic fungi interact with both the variety. This had 
confirmed that the extracted and prepared mRNA by this method can be effectively used for further downstream molecular application like gene cloning by RT-PCR, reverse transcription or the construction of cDNA libraries (Leite et al., 2012). These findings have an impact on to improve the molecular study of host-fungi interaction.

In conclusion this study represents a reproducible, efficient, reliable and effective RNA extraction method. In combination of TRIZOL and CTAB buffer with the use of acid-phenol resulted in high quality and purity of RNA from A. flavus. For the various filamentous fungi the current protocol is highly recommended for efficiently isolation of good-quality total RNA.

\section{Acknowledgements}

This work was carried out at the Department of Biotechnology, Junagadh Agricultural University. This work was supported by confederation of Indian industry.

\section{References}

Asan. A. (2004). Aspergillus, Penicillium and related species reported from Turkey. Mycotaxon, 89(1): 155-157.

Bakri, Y., Magali, M. and Thonart, P. (2009). Isolation and identification of a new fungal strain for amylase biosynthesis. Polish Journal of Microbiology, 58(3): 269-273.

Chomczynski, P. and Sacchi, N. (2006). The single-step method of RNA isolation by acid guanidinium thiocyanate phenol chloroform extraction: Twenty-something years on. Nature Protocols 1(2): 581-585. doi: $10.1038 /$ nprot.2006.83

Cotty, P. J. and Garcia, R. J. (2007). Influences of climate on aflatoxin producing fungi and aflatoxin contamination. International Journal of Food Microbiology, 119 (1): 109-115.
Dorner, J. W. and Cole, R. J.(2002). Effect of application of nontoxigenic strains of Aspergillus flavus and A. parasiticus on subsequent aflatoxin contamination of peanuts in storage. Journal of stored products research, 38(4): 329-339.

Geiser, D. (2009). Sexual structures in Aspergillus; morphology, importance and genomics. Medical mycology; official publication of the Internationl Society for Human and animal mycology. Pp: 21-26.

Geoghegan, I. A., Emes, R. D., Archer, D. B. and Avery, S. V. (2019). Method for RNA extraction and transcriptomic analysis of single fungal spores. MethodsX, 7: 50-55.

Georgianna, D. R., Fedorova, N. D, Burroughs, J. L., Dolezal, A. L., Bok, J. W. and HorowitzBrown, S. (2010). Beyond aflatoxin: four distinct expression patterns and functional roles associated with Aspergillus flavus secondary metabolism gene clusters. Molecular plant pathology, 11(2): 213-26.

Griffin, D.W., Kellogg, C. A., Peak, K. K. and Shinn, E. A. (2002). A rapid and efficient assay for extracting DNA from fungi. Letters in Applied Microbiology, 34(3): 210-214

Klich, M. A. (2007). Aspergillus flavus: the major producer of aflatoxin. Molecular plant pathology, 8(6): 713-722.

Kumeda Y. and Asao, T. (2001). Heteroduplex panel analysis, a novel method for genetic identification of Aspergillus section Flavi Strains. Applied and Environmental Microbiology, 67(9): 4084-4090.

Leite, G., Magan, N. and Medina, A. (2012). Comparison of different bead-beating RNA extraction strategies: An optimized method for filamentous fungi. Journal of microbiological methods. 88: 413-418.

Lim, N. Y. N., Roco, C. A. and Frostegard, A. (2016). Transparent DNA/RNA coextraction workflow protocol suitable for inhibitor-rich environmental samples that focuses on complete DNA removal for transcriptomic analyses. Frontiers in Microbiology 7: 1588. 
Machida, M. and Yamada, O. (2008). Genomics of Aspergillus oryzae: learning from the history of koji mold and exploration of its future. DNA Research, 15(4): 173-183.

Manonmani, H. K., Anand, S., Chandrashekar, A. and Rati, E. R. (2005): Detection of aflatoxigenic fungi in selected food commodities by PCR. Process Biochemistry, 40(8): 2859-2864.

Patyshakuliyeva, A., Makela, M. R., Sietio, O. M., de Vries, R. P. and Hilden, K. S. (2014). An improved and reproducible protocol for the extraction of high quality fungal RNA from plant biomass substrates. Fungal Genetics and Biology, 72: 201- 206 doi:10.1016/j.fgb.2014.06.001

Perrone, G., Susca, A., Cozzi, G., Ehrlich, K., Varga, J., Frisvad, J. C., Meijer, M., Nooim, P.; MahakamchanakuL, W. and Samson, R. A. (2007). Biodiversity of Aspergillus species in some important agricultural products. Studies in mycology, 59(1): 53-66.

Poon, N. K., Othman, R. Y., Mebus, K. and Chee, H. T. (2019). Optimization of CTAB-based RNA extraction for in planta Fusarium oxysporum f. sp. cubense gene expression study. Sains Malaysiana, 48(10): 2125-2133. 10.17576/jsm-20194810-07.

Rubio-Pina, J. A. and Zapata-Perez, O. (2011). Isolation of total RNA from tissues rich in polyphenols and polysaccharides of mangrove plants. Electronic Journal of Biotechnology 14(5): 10.
Sanchez-Rodriguez, A., Portal, O. and Rojas, L. E. (2008). An efficient method for the extraction of high-quality fungal total RNA to study the Mycosphaerella fijiensis-Musa spp. Interaction. Molecular Biotechnology, 40(3):299- 305 doi:10.1007/s12033-008-9092-1.

Schumann, U. Schumann,U., Smith, N. and Wang, M. (2013). A fast and efficient method for preparation of high-quality RNA from fungal mycelia. BMC research notes. 6: 71.

Shu, C., Sun, S., Chen, J., Chen, J. and Zhou, E. (2014). Comparison of different methods for total RNA extraction from sclerotia of Rhizoctonia solani. Electronic Journal of Biotechnology, 17(1): 50-54.

Tan, S. C. and Yiap, B. C. (2009) DNA, RNA and protein extraction: the past and the present. (2009). DNA, RNA, and protein extraction: the past and the present. Journal of biomedicine \& biotechnology.

Wang, L. and Stegemann, J. P. (2010). Extraction of high quality RNA from polysaccharide matrices using cetyltrimethylammonium bromide.

Biomaterials. 31(7): 1612-1618.

Yamamoto, N., Kimura M., Matsuki H. and Yanagisawa Y. (2010): Optimization of a real-time PCR assay to quantitate airborne fungi collected on a gelatin filter. Journal of Bioscience and Bioengineering, 109(1): 83-88.

\section{How to cite this article:}

Virali Antala, Hemangini Chaudhari, Nidhi Radadiya, Hiral Desai, B. A. Golakiya and Gajera, H. P. 2020. Optimization of CTAB-based RNA Extraction Method for Aspergillus flavus. Int.J.Curr.Microbiol.App.Sci. 9(08): 325-332. doi: https://doi.org/10.20546/ijcmas.2020.908.038 